\title{
Corrosion Resistance and Physical-Mechanical Properties of Reinforced Mortars with and without Carbon Nanotubes
}

\author{
Nikolaos Chousidis ${ }^{1,2}$, Aggeliki Zacharopoulou ${ }^{2}$, Christos Zeris ${ }^{1}$, George Batis ${ }^{2}$ \\ ${ }^{1}$ School of Civil Engineering, Department of Structural Engineering, National Technical University of Athens, Athens, Greece \\ ${ }^{2}$ School of Chemical Engineering, Department of Material Science \& Technology, National Technical University of Athens, \\ Athens, Greece \\ Email: nickhous@central.ntua.gr, aggeliki.zaxaropoulou@gmail.com, zeris@central.ntua.gr, gbatis@central.ntua.gr
}

How to cite this paper: Chousidis, N., Zacharopoulou, A., Zeris, C. and Batis, G. (2022) Corrosion Resistance and Physical-Mechanical Properties of Reinforced Mortars with and without Carbon Nanotubes. Journal of Materials Science and Chemical Engineering, 10, 1-23. https://doi.org/10.4236/msce.2022.101001

Received: November 22, 2021

Accepted: January 16, 2022

Published: January 19, 2022

Copyright ( 2022 by author(s) and Scientific Research Publishing Inc. This work is licensed under the Creative Commons Attribution International License (CC BY 4.0).

http://creativecommons.org/licenses/by/4.0/

(c) (i) Open Access

\begin{abstract}
Following the evolution of currently enforced Performance Based Design standards of reinforced concrete (RC) structures for durability, the designer, rather than complying with given prescriptive limits, may instead specify a cementitious mix design that is proven to exhibit a code prescribed resistance level (class) to a given exposure environment. Such compliance will lead to the protection of the steel reinforcement from corrosion and the cementitious mortar from degradation, during the design lifespan of the structure, under aggressive environmental exposure conditions such as, marine or deicing salts and carbonation. In this context, the enhancement of the physical and durability properties of common cement-based mortars under chloride exposure are experimentally investigated herein. In particular, the experimental program reported herein aims to evaluate the influence of incorporating multi-walled carbon nanotubes on the physical and mechanical properties of reinforced mortars against chloride ions. Furthermore, the anticorrosion protection of cementitious composites prepared with nanomaterials at $0.2 \% \mathrm{w} / \mathrm{w}$ is further investigated, by comparing all test results against reference specimens prepared without any additive. Electrochemical (Half-cell potential, corrosion current) and mass loss of reinforcement steel measurements were performed, while the porosity, capillary absorption and flexural strength were measured to evaluate the mechanical and durability characteristics of the mortars, following a period of exposure of eleven months; SEM images coupled with EDX analysis were further recorded and used for microstructure observation. The test results indicate that the inclusion of the nanomaterials in the mix improved the durability of the mortar specimens, while the nano-modified composites exhibited higher chloride penetration resistance and flexural strength
\end{abstract}


than the corresponding values of the reference mortars. The test results and the comparison between nanomodified and reference mortars showed that the use of CNTs as addition led to protection of steel reinforcing bars against pitting corrosion and a significant improvement in flexural strength and porosity of the mortars.

\section{Keywords}

Cement Mortars, Steel Reinforcing Bars, Corrosion, Chloride Ingress, Flexural Strength, Porosity, Capillary Absorption, Electrochemical Properties, Carbon Nanotubes

\section{Introduction}

Fundamental research undertaken in recent years focuses on the design and development of modified cementitious materials with improved mechanical and durability properties. With the development of nanotechnology, cement-based materials can now also be modified at the nanoscale with suitable nanoscale additions, taking advantage of their superior properties, such as, among others, carbon nanotubes (CNTs). Results from recent experimental studies on CNTs reinforced cementitious composites confirmed that their mechanical properties were markedly improved, paving the way to the introduction of these additives in ordinary concrete construction.

Concrete using cements with different cementitious admixtures is the most common building material in the construction industry. The most important factors of its widespread use are the relatively low production costs, the ease of production at the place of use using locally available aggregates, its high compressive strength, and the ease of shaping the form due to its young thixotropic characteristics. At the same time, concrete has low tensile strength and, therefore, works in most practical cases in cooperation with reinforcement; due to its porous structure, it allows the diffusion of corrosive ions and gaseous pollutants through its mass, which act corrosively on the reinforcement. Furthermore, its modulus of elasticity, which, like strength, is also directly related to the quality of the concrete (porosity), may also be low due to improper mix design, poor or insufficient curing and/or poor compaction during concreting.

Further to that, the exposure of concrete to carbon dioxide (carbonation of concrete) reduces the alkalinity $(\mathrm{pH})$ of the concrete: due to the hydrated lime $\mathrm{Ca}(\mathrm{OH})_{2}$, the $\mathrm{pH}$ of the concrete, which initially ranges between 12.5 and 13.9, drops to values below 9.0. As a result, the embedded steel corrodes strongly, as it switches from passive to active state [1].

Corrosion products of steel reinforcement, due to the larger volume that they have compared to steel, exert internally tensile stresses on the concrete that result in the creation initially of internal cracks, gradually propagating to cover concrete spalling, while reducing the reinforcement/concrete bond. It should be 
noted that the action of chlorides and carbon dioxide $\left(\mathrm{CO}_{2}\right)$ is synergistic. Thus, in the case of coastal structures, while an amount of $\mathrm{Cl}^{-}$is bound by AFM phase to form chloride salts and reduce the permeability of the concrete, $\mathrm{CO}_{2}$ reacts with the hydrated lime $(\mathrm{CH})$ to form calcium carbonate $\mathrm{CaCO}_{3}$ with the direct effect of $\mathrm{pH}$ reduction and, consequently, corrosion of the reinforcement [1].

From the above, it is obvious that in concrete works that are exposed to strongly chloride and carbonate corrosive environment, such as sea water, antifreeze salts, corrosive soils, industrial areas, etc., it is necessary and, nowadays, mandatory in currently enforced design [2] and product standards [3] to improve the physical-chemical properties of concrete and its corrosion protective role of the reinforcement. So far, the main methods of protection of RC elements include the use of coatings, cathodic protection, corrosion inhibitors, addition of finer pozzolanic materials, etc. The above methods have several disadvantages such as 1) the high maintenance costs of electrochemical methods, 2) the possible toxicity of corrosion inhibitors, and 3 ) the relatively slow effectiveness regarding the use of pozzolans. Following the evolution of nanomaterials, nanotechnology can also be used to produce new composite mortars with significantly increased strength and durability properties, for use in RC structures exposed to highly corrosive environments and/or extreme operating conditions.

There are two different structures of CNTs, the monofilament carbon nanotubes (SWCNTs) [4] [5] and the multilayer carbon nanotubes (MWCNTs) [6] [7]. Monofilament carbon nanotubes consist of a graphite sheet wrapped in a specified direction in a cylindrical shape. SWCNTs can be closed at their ends by "caps" with a hemispherical structure; their diameter does not exceed $2 \mathrm{~nm}$, while their length often reaches $5 \mu \mathrm{m}$. Multilayer carbon nanotubes consist of a series of graphite sheets, which are wrapped concentrically into each other. The diameter of MWCNTs usually ranges between $3 \mathrm{~nm}$ and $250 \mathrm{~nm}$. The distance between their walls is close to the distance between two graphite sheets $(0.335 \mathrm{~nm})$. Of particular research interest in recent years are MWCNTs comprising two graphite sheets (Double-Walled Carbon Nano-Tubes-DWCNTs) whose properties are similar to those of monofilament CNTs. They have the advantage that they are more chemically modified than monofilaments, to which some double bonds need to be broken in order to, chemically, add a group. In this way gaps are created in the structure of monofilament CNTs and therefore their electrical and mechanical properties are changed, in contrast to DWCNTs in which only the outer wall is modified.

Carbon nanotubes, in addition to their excellent electrical/thermal properties, exhibit very high tensile strength [8] and modulus of elasticity [9] [10] due to the covalent bonds ( $\mathrm{sp} 2$ bonds) between the carbon atoms embedded in their grid. It has been reported [11] that the modulus of elasticity of CNTs exceeds $1 \mathrm{TPa}$ while, in comparison, steel (high strength) reaches a maximum of $200 \mathrm{GPa}$. In addition, the tensile strength of CNTs is between 65 to $93 \mathrm{GPa}$, compared to that of conventional high strength structural steel ranging between 1 to $2 \mathrm{GPa}$ [12] Therefore, by mixing carbon nanotubes in the mortar mix, a significant improvement in the tensile strength of the mortar would be expected, which, in conven- 
tional mortar is extremely low (approximately $\approx 1: 10$ of the corresponding compressive strength); such an increase will also enhance the resistance in other tension related modes of failure, such as bending [13].

MWCNTs have a specific gravity of $\approx 0.18$, a specific surface area $>200 \mathrm{~m}^{2} / \mathrm{g}$ and are added to the mortar mixture in small dosages [14]. The improvement of the mechanical properties of nanomodified mortar is due to the development of Van Der Waal forces between the nanomaterial and the hydration products (C-S-H and $\mathrm{C}-\mathrm{H}$ ) that prevent the material from breaking during tensile rupture through bridging between the cracked surfaces [15]. But apart from the excellent mechanical properties, carbon nanotubes have the ability to fill the gap between the hydration products and the unhardened cement grains, thus reducing the porosity at the micro- and nano-scales, as well as the permeability of the mortar. These factors above lead to an increase in the density of the structural material and a corresponding reduction in the corrosion of the reinforcement [16].

However, the experimental results in the literature on the effect of introducing CNTs on the corrosion rate of steel embedded in mortar samples, are contradictory. The addition of CNTs caused higher corrosion intensities for cement mortars with up to $0.5 \%$ CNT subject to simulated sea water and accelerated carbonation exposure [17]. On the other hand, Gdoutos et al. [18] reported that the inclusion of $0.1 \mathrm{wt} \%$ CNTs decreased the corrosion rate and significantly increased the resistance to corrosion by delaying the onset of the corrosion reaction (initiation period). The authors further studied the influence of high CNTs content $(0.5 \mathrm{wt} \%)$ on the corrosion behavior of mortars and showed that by adding higher amounts of CNTs, the reinforced mortars exhibited higher corrosion rate compared to that of mortars with $0.1 \mathrm{wt} \%$ CNTs. According to the authors, the observed delay in the onset of corrosion was due to a marginal decrease in permeability, leading to a reduction in the ingress of aggressive agents. It was concluded, however, that this increased tendency to corrosion needed further investigation. Hassan et al. [19] also showed that the corrosion of reinforcing steel embedded in CNT mortars was affected by its diameter: more specifically, steel reinforcement of $16 \mathrm{~mm}$ diameter had a lower corrosion resistance than that of steel reinforcement of diameter $12 \mathrm{~mm}$. It should be noted, however, that the behavior of CNT modified mortars also depends on the physio-mechanical characteristics of the CNTs, something which is investigated herein by using CNTs with different mechanical characteristics compared to Gdoutos et al. [18], as described further on.

Consequently, the main objective of the present experimental investigation is the study of the utilization of multi-walled carbon nanotubes (MWCNTs) for the production of high-performance cementitious mortars with improved physicalmechanical properties and chloride penetration resistance.

\section{Experimental Set-up}

In order to investigate the physical-mechanical properties and chloride penetra- 
tion resistance of nano modified mortars, a comprehensive test program was established by the Laboratories of Reinforced Concrete and Materials Science \& Engineering of the Schools of Civil and Chemical Engineering at the National Technical University of Athens, respectively, under European Union research grant OPS ESPA 2014-2020. The scope of the program comprised physical-mechanical as well as durability tests, as subsequently described, to compare the experimental response of both nano modified and reference materials.

\subsection{Materials, Chemical Properties, and Specimen Preparation}

CEM I $42.5 \mathrm{~N}$ cement was used as a binder, while calcareous fine aggregates ( 0 $4 \mathrm{~mm}$ ) and water from the potable supply network were utilized in the preparation of the mixtures. In all mixture groups a constant ratio of raw material weights was used, namely cement: sand: total water $=1: 3: 0.65$, which, for the aggregate used, corresponded to an active water cementitious (w:c) ratio of 0.59 . The choice of a relatively high w:c ratio was intentional, so as to produce relatively low strength and high porosity mortars, representative of common mortar production, which would highlight the effect of CNTs in this type of common structural material. The steel reinforcement bars to be concreted were cleaned according to ISO/DIS 8407.3 with a solution of hydrochloric acid $(\mathrm{HCl})$ containing an organic inhibitor for a period of twenty (20) minutes in order to remove the oxides and impurities on their surface. The bars were then immersed in deionized water and acetone to remove grease and oil from their surface and were subsequently placed in a glass desiccator up to concreting to prevent corrosion by atmospheric air. Finally, the reinforcement steel bars were weighed on a digital balance $(0.1 \mathrm{mg})$ and connected with a copper wire so as to ensure the electrical continuity. The specimens were removed from the molds after 24 hours, remained in water for seven (2) days and were then partially immersed in 3.5 wt\% solution.

For the physico-mechanical tests and the electrochemical measurements the following specimens were constructed in the lab:

- Half-cell potential ( $H C P$ ): $100 \mathrm{~mm}$ reinforced mortars with a diameter of $\phi 50 \mathrm{~mm}$ in which a $\phi 10 \mathrm{~mm}$ diameter, $100 \mathrm{~mm}$ long Tempcore B500C reinforcing steel bar was axially secured.

- Corrosion current. $100 \mathrm{~mm}$ reinforced mortars with a diameter of $\phi 50 \mathrm{~mm}$ in which a $\phi 10 \mathrm{~mm}$ diameter, $100 \mathrm{~mm}$ long Tempcore B500C reinforcing steel bar was axially secured.

- Flexural strength: Prismatic specimens with dimensions $40 \times 40 \times 160 \mathrm{~mm}^{3}$.

- Capillary porosity: Cubic specimens with dimensions $50 \times 50 \times 50 \mathrm{~mm}^{3}$.

In the mix design of reinforced cement mortars two (2) groups of specimens were constructed (Figure 1): 1) Eighteen (18) specimens reinforced with the addition of $0.2 \%$ by weight CNTs (designated CNT), and 2) and Eighteen (18) reference specimens without addition of nanomaterials (designated as REF). The nanomaterials being supplied by SAT nano Technology Material Co. Ltd; in Ta- 
ble 1 the physical properties of CNTs are summarized, while the mix characteristics of the two specimen groups are given in Table 2 . As can be seen, the nanomaterials used in the present study are shorter and have higher surface specific comparing to Gdoutos et al. [18] research; this is beneficial to fill the cracks and pores in cement matrix thus resulting a solid mortar with increased density and reduced porosity. For compaction, mechanical vibration was performed during casting to reduce the air content of the mixtures. The reinforcing bars were $20 \mathrm{~mm}$ away from the base of the mold so as not to be directly exposed to corrosion conditions (Figure 1(b)). The surface on the top of the mortar specimens and the protruding part of the reinforcement were then covered with Araldite epoxy resin to prevent galvanic corrosion. The specimens were water-cured for seven days with relative humidity $\mathrm{RH} \geq 99 \% \pm 1 \%$ and temperature $\mathrm{T}=25^{\circ} \mathrm{C} \pm$ $1^{\circ} \mathrm{C}$ to avoid cracking due to hydration heat release.

Table 1. Physical properties of CNTs used in the study and in Gdoutos et al. [18] research.

\begin{tabular}{ccc}
\hline \multicolumn{3}{c}{ Physical properties of CNTs } \\
\hline \\
CNTs used in the study & Gdoutos et al. [18] \\
\hline Diameter & $2-10 \mathrm{~nm}$ & $20-40 \mathrm{~nm}$ \\
Length & $10-30 \mu \mathrm{m}$ & $\geq 10 \mathrm{um}$ \\
Color & & Black powder \\
Surface specific area & $>500 \mathrm{~m}^{2} / \mathrm{g}$ & $>200 \mathrm{~m}^{2} / \mathrm{g}$ \\
\hline
\end{tabular}

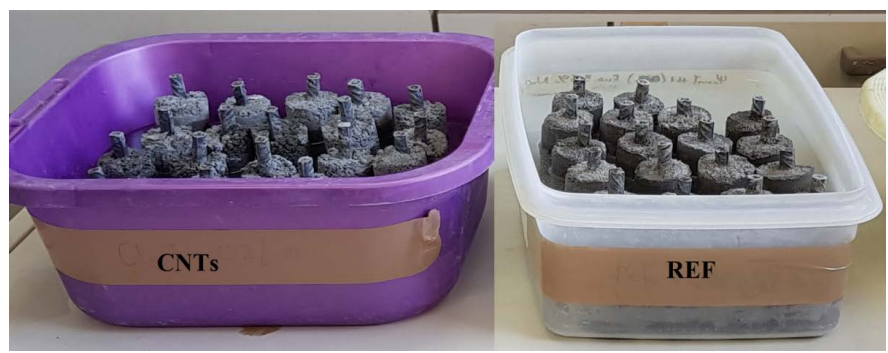

(a)

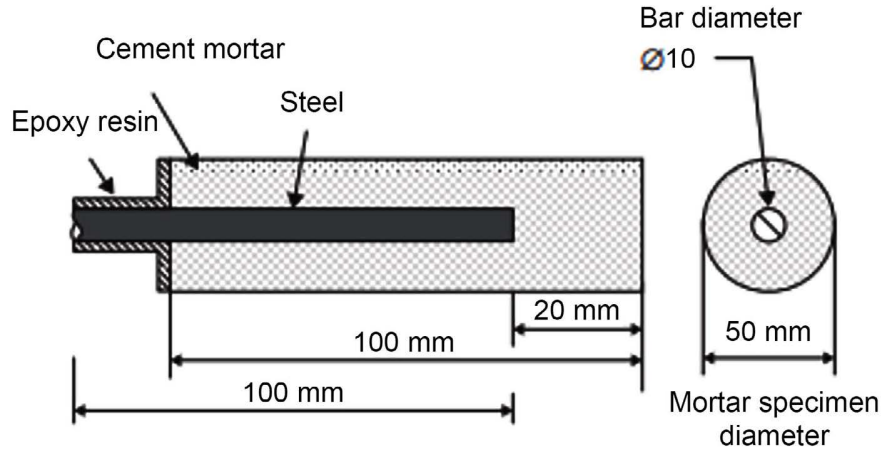

(b)

Figure 1. Mortar test specimens prepeared in the lab; (a) photos; and (b) sectional details. 
Table 2. Mixture quantities (g) of raw materials for mortars preparation.

\begin{tabular}{ccccc}
\hline \multicolumn{5}{c}{ Mix design of the mortars } \\
\hline & CNT & REFERENCE & & 0.65 \\
Cement & 1900 & 1900 & Total w: c ratio & $(0.59$ active \\
Fine aggregates $(0-4 \mathrm{~mm})$ & 5700 & 5700 & & w:c $)$ \\
\hline Water & 1235 & 1235 & Cement: limestone sand & $1: 3$ \\
CNTs & 3.8 & 0 & & \\
\hline
\end{tabular}

\subsection{Description of the Test Methods and Techniques}

\subsubsection{Three-Point Bending Test}

The bending strength of nanocomposite and conventional mortars was measured by loading prismatic beams of dimension $40 \times 40 \times 160 \mathrm{~mm}^{3}$ (Figure 2) with a span length $120 \mathrm{~mm}$, namely three times of the width $(40 \mathrm{~mm})$. The flexural strength of the mortar was obtained using Equation (1):

$$
\sigma_{f l}=\frac{3 F l}{2 b d^{2}}
$$

where, $\sigma_{f l}$ is the flexural strength $(\mathrm{MPa}), F$ is the maximum force at fracture (N), $L$ is the span length ( $\mathrm{mm}$ ) and $b, d$ are the width and the height ( $\mathrm{mm}$ ) of the specimen.

\subsubsection{Porosity and Capillary Absorption Measurements}

The apparent density and open porosity of mortars were estimated using vacuum saturation; for the tests, cubic specimens with dimensions $50 \times 50 \times 50$ $\mathrm{mm}^{3}$ were used, as depicted in Figure 3. The test samples were full-dried in an oven at $110^{\circ} \mathrm{C} \pm 5^{\circ} \mathrm{C}$, before being subjected to vacuum saturation with water for $24 \mathrm{~h}$. Following, the open porosity $(P)$ was determined using Equation (2) below:

$$
P(\%)=\frac{W_{s}-W_{d}}{W_{s}-W_{h}}
$$

where, $W_{s}$ is the liquid-saturated mass of sample (g), $W_{d}$ the oven dried mass (g) and $W_{h}$ the mass of the immersed liquid-saturated sample $(\mathrm{g})$.

The capillary absorption is considered as a function of the density, the viscosity, and the surface tension of the liquid used for the test, and the pore structure of the test sample. In the present experimental study, the sorptivity was measured on cubic specimens $50 \times 50 \times 50 \mathrm{~mm}^{3}$ using the method proposed by Gummerson et al. and Hall et al. [21] [22]. During the test, the level of methanol was constantly $2-3 \mathrm{~mm}$ over the bottom side of the specimens, while the specimen's temperature was continuously recorded. The volume of liquid absorbed per square unit of absorbing surface area $i$ was estimated using Equation (3) below. The sorptivity $\left(S_{i}\right)$ of the specimens was estimated as the slope of the corresponding $i$ vs $\sqrt{t}$ graph, in accordance with Equation (4), below:

$$
i=\frac{d_{m}}{a \cdot d}
$$




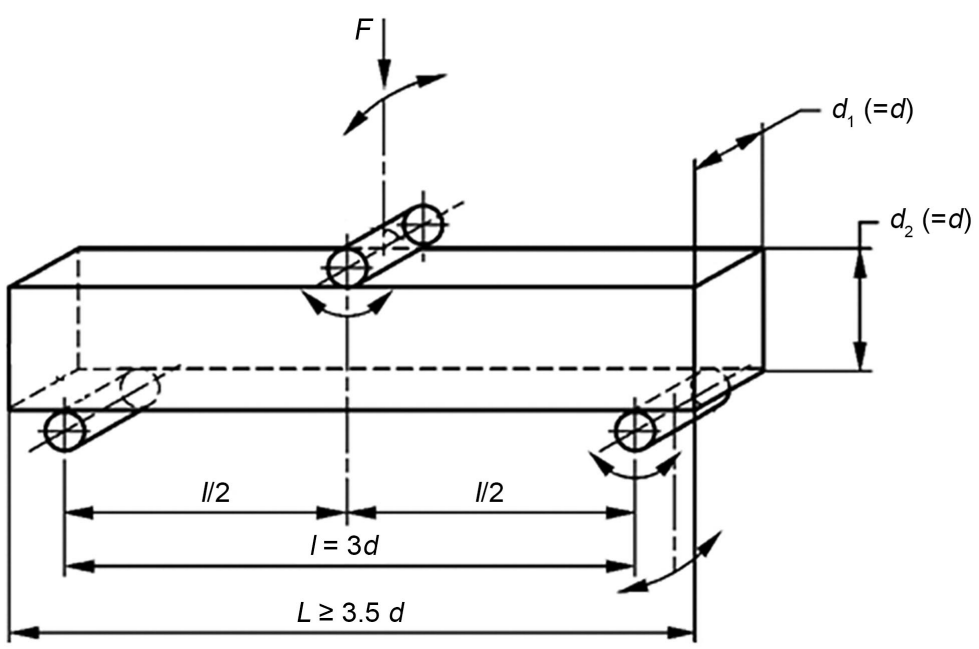

(a)

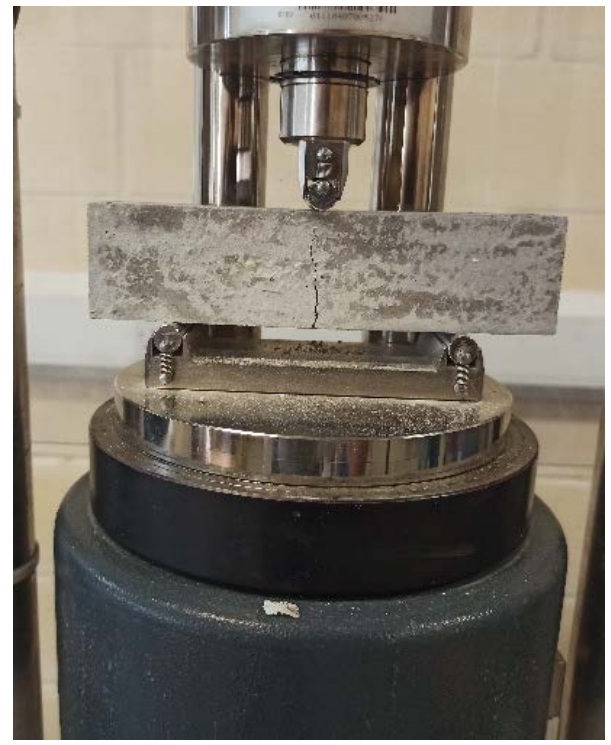

(b)

Figure 2. Three-point bending test following EN 12390-5 [20]: (a) schematic representation; and (b) flexure test set-up.

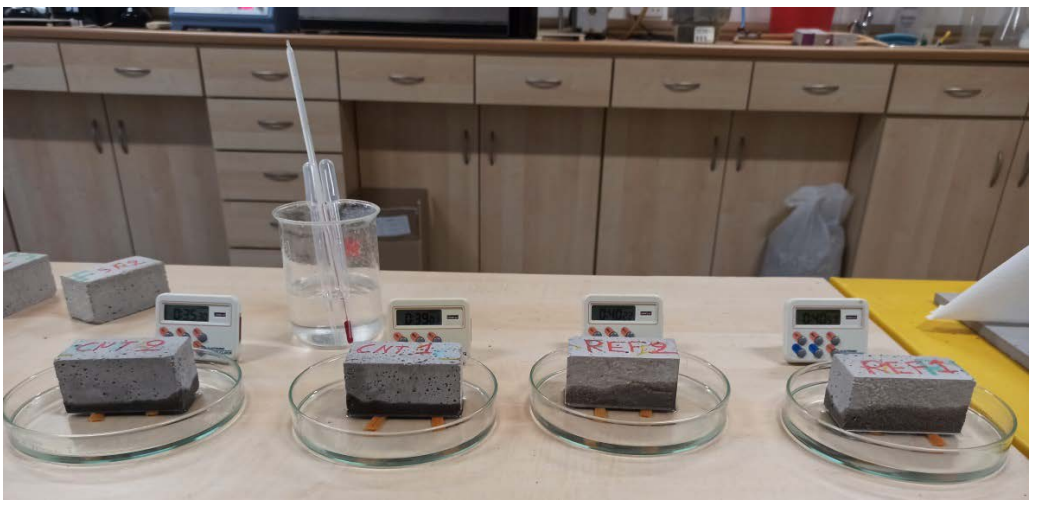

Figure 3. Experimental set-up for the capillary absorption measurements at the building materials. Laboratory of the University of Cyprus. 


$$
i=S_{i} \cdot \sqrt{t}
$$

where, $d_{m}$ is the mass gain in $\mathrm{g}, \mathrm{a}$ is the surface area of the immersed specimen side in $\mathrm{mm}^{2}$ and $d$ is the density of absorbing liquid in $\mathrm{g} / \mathrm{mm}^{3}$.

\subsubsection{Half-Cell Potential Measurements}

Half-cell potential measurements were conducted for a period of 11 months according to ASTM C-867 [23], in order to evaluate the corrosion rate of steel reinforcing bars. The half-cell potential difference was measured using a highimpedance voltammeter and a reference electrode $(\mathrm{Ag} / \mathrm{AgCl})$, using the test setup shown in Figure 4.

In Table 3 the corrosion potential against the probability of the steel for corrosion are summarized. Monitoring of reinforcement corrosion was affected by recording the corrosion potential of the open circuit as a function of the exposure time to chloride solution every 7 days, according to the standard ASTM C876-87 [23]. The value of the corrosion potential of the reinforcement in concrete as a function of time is an indication of the state of the reinforcement in the concrete, i.e., whether the steel reinforcement is in active or passive state.

\subsubsection{Corrosion Current Measurements}

A Potensiostat/Galvanostat Model 263A from EG\&G Princeton Applied Research was used for the test, with the associated software for data acquisition and analysis, in order to analyze the test data. The potential scan range was $\pm 10 \mathrm{mV}$
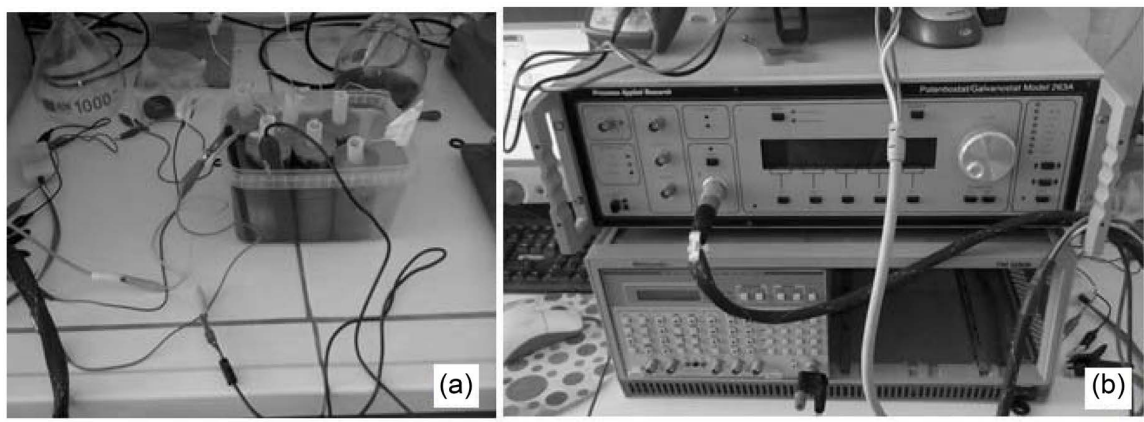

Figure 4. Icorr measurements (a) and Potentiostat/Galvanostat Model 263A (b) used for the experiments [24].

Table 3. Possibility of corrosion for steel reinforcing bars embedded in cement mortars using HCP method according to ASTM C 876-87 [23].

\begin{tabular}{ccc}
\hline & Corrosion risk of steel & \\
\hline $\mathrm{Cu} / \mathrm{CuSO}_{4}$ & $\mathrm{Ag} / \mathrm{AgCl}(4 \mathrm{M} \mathrm{KCl})$ & Corrosion condition \\
$E \geq-200 \mathrm{mV}$ & $E \geq-106 \mathrm{mV}$ & Low $(<10 \%$ risk $)$ \\
$-350 \mathrm{mV}$ to $-200 \mathrm{mV}$ & $-106 \mathrm{mV}$ to $-256 \mathrm{mV}$ & Uncertain (intermediate risk) \\
$E<-350 \mathrm{mV}$ & $E<-256 \mathrm{mV}$ & Very high (>90\%) \\
$E<-500 \mathrm{mV}$ & $E<-406 \mathrm{mV}$ & Severe
\end{tabular}


from the open circuit and the scan rate was $0.1 \mathrm{mV} / \mathrm{s}$. The experimental set-up comprised the steel reinforcement bars that represented the working electrode, a $\mathrm{Ag} / \mathrm{AgCl}$ electrode which represented the reference electrode, and a carbon bar as a counter electrode.

The Linear Polarization Resistance (LPR) Technique is a rapid and non-destructive electrochemical method for monitoring corrosion rate in real time. In LPR measurements the reinforcing steel is perturbed by a small amount from its equilibrium potential. This can be accomplished potentiostatically by changing the potential of the reinforcing steel by a fixed amount, $\Delta E$, and monitoring the current decay, $\Delta I$, after a fixed time [25].

Based on the Stern-Geary method, the polarization resistance is calculated using Equation (5).

$$
R_{p}=\frac{\Delta E}{\Delta I}
$$

From Equation (5), the corrosion rate $I_{\text {corr }}$ can be calculated by Equation (6):

$$
I_{\text {corr }}=\frac{\beta_{a} \beta_{c}}{2.303\left[\beta_{a}+\beta_{c}\right]} \times \frac{1}{R_{p}}
$$

where $\beta_{a} \beta_{c}$ are the anodic and the cathodic Tafel slopes, respectively.

The current (I) was calculated using Equation (7), where $A$ is the surface area of steel that has been polarized.

$$
I=\frac{I_{\text {corr }}}{A}
$$

The mass loss was calculated by Equation (8):

$$
\beta=1+\frac{I M t}{z F}
$$

where $\beta$ is the mass loss of the steel rebar $(\mathrm{g}), I$ is the corrosion rate $(A), M$ is the atomic mass of the metal (equal to $56 \mathrm{~g}$ for $\mathrm{Fe}$ ), $t$ is the time of exposure (s), $z$ is the ion chance $\left(=2\right.$ for $\left.\mathrm{Fe} \rightarrow \mathrm{Fe}^{+}+2 \mathrm{e}^{-}\right)$, and $F$ is the Faraday's constant 96.500 $(A \times s)$.

\subsubsection{Scanning Electron Microscopy (SEM)}

The microscopical analyses were caried out on the fresh fractured prismatic specimens after the flexural strength test. As a final means of investigation of the nano modified mortars, and in order to establish the suitability of the CNT dispersion method and the progress of the hydration products with time, portions of the mortar samples after strength testing were obtained and analyzed visually using a JEOL, JSM-6610 LV SEM with a maximum resolution of $3.0 \mathrm{~nm}$ at $30 \mathrm{kV}$ (in the high vacuum mode) and a magnification of $5 \mathrm{x}-300.000 \mathrm{x}$. The optical observations were performed using a Backscattered Electron Detector (BSE). Prior to the analysis, the samples were sputter coated with gold (50 nm thick) to make their surface conductive. The size, shape and morphology of the crystals were observed, and the structure of samples was investigated. The comparisons of the two mortar groups are given in the subsequent section. 


\section{Results and Discussion}

\subsection{Porosity and Sorptivity Measurements}

The results of the porosity measurements performed on cement mortars using vacuum saturation at 7,28, 120 and 240 days are shown in Figure 5, where it can be seen that both examined groups exhibit a gradual reduction in their porosity from 7 to 240 days. From the results it is also evident that the initial capillary porosity of the nano modified composites is lower than that of the REF mortars without any addition, in agreement with test results reported for different mortar mixes and CNT concentrations by other investigators. The influence of CNTs in the porosity of the mortars was more pronounced at 7 days, while it was observed that the mixtures tend to have equal porosity values at later ages. In particular, the nano-modified mortars demonstrated around 3\% lower value of porosity than the reference mixture at 7 days, while the corresponding difference is reduced to $0.8 \%$ at 28 days. It was therefore observed that the addition of CNTs acts as a filler in the cementitious mixtures, thereby reducing further the pore size of the hardened composite and generating more nucleation sites to accelerate hydration reactions (see also the SEM analysis further on).

The influence of CNTs on the physical properties of mortars has been studied by several researchers [26] [27], who observed that the incorporation of nanomaterials can reduce significantly the mortar porosity, thereby potentially improving the durability of cement-based materials. This was further corroborated by microscopy analyses, that reveal a denser microstructure and a bridged network in the voids and cavities present in mortars containing CNTs; the latter was attributed to the length-to-diameter ratio of carbon nanotubes used in these studies, which effectively fill the cracks and pores in cement matrix thus resulting a solid mortar with increased density and reduced porosity. This increase in the density of the CNT modified mortars, relative to the plain REF specimens was also depicted in the relatively low strength REF mortar of the present study (Figure 5, Figure 6), where an increase in the density of the two mixtures was obtained from the $7^{\text {th }}$ day, consistently increasing with time to 240 days after casting (Figure 6).

Figure 7 depicts the progress of capillary absorption over time, for all mortars tested. In general, low capillary absorption in nanocomposites indicate that the adhesion of CNTs is strong, and no capillary voids were generated on the interfacial transition zone (ITZ) of the specimens [28] [29]. As can be observed, the sorptivity is strongly affected by the carbon nanotubes addition and the curing time. The results suggest that the sorptivity of mortars incorporating CNTs decreased throughout the curing time in atmospheric air. From the test results, the CNT group demonstrated lower absorption values compared to the CNTs-free analogue by $22.9 \%, 21.8 \%$ and $22.1 \%$ at 7,28 and 120 days, respectively. The results are broadly in agreement with the porosity results reported in this study; nanomaterials are in fact finer than cement grains, and therefore fill the pores of mortar, decreasing its sorptivity. 


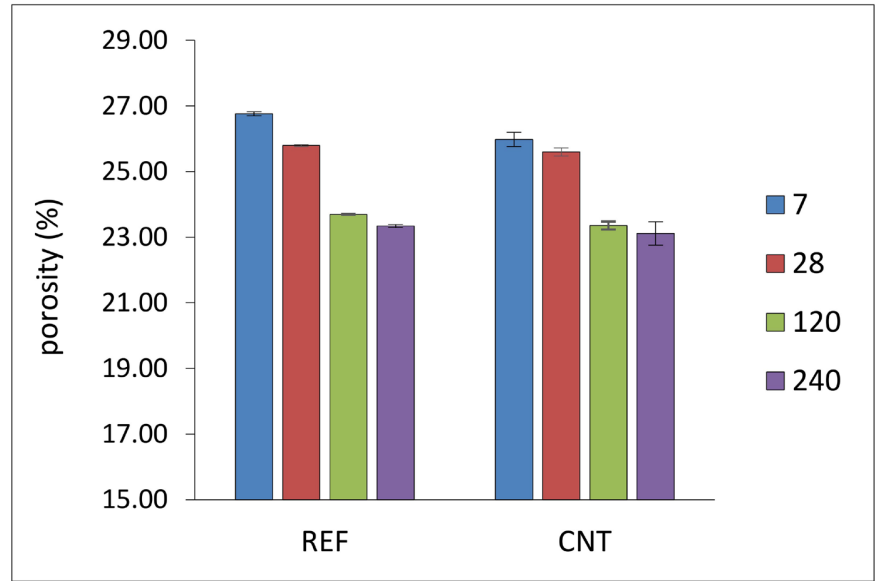

Figure 5. Average porosity (\%) values of mortars with and without CNTs.

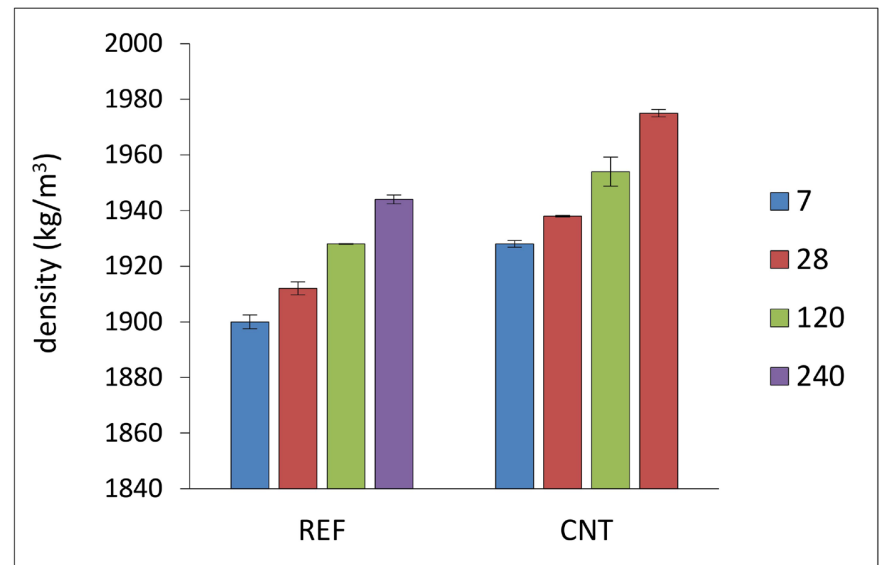

Figure 6. Densities $\left(\mathrm{kg} / \mathrm{m}^{3}\right)$ of cement mortars with and without CNTs at times: 7, 28, 120 and 240 days.

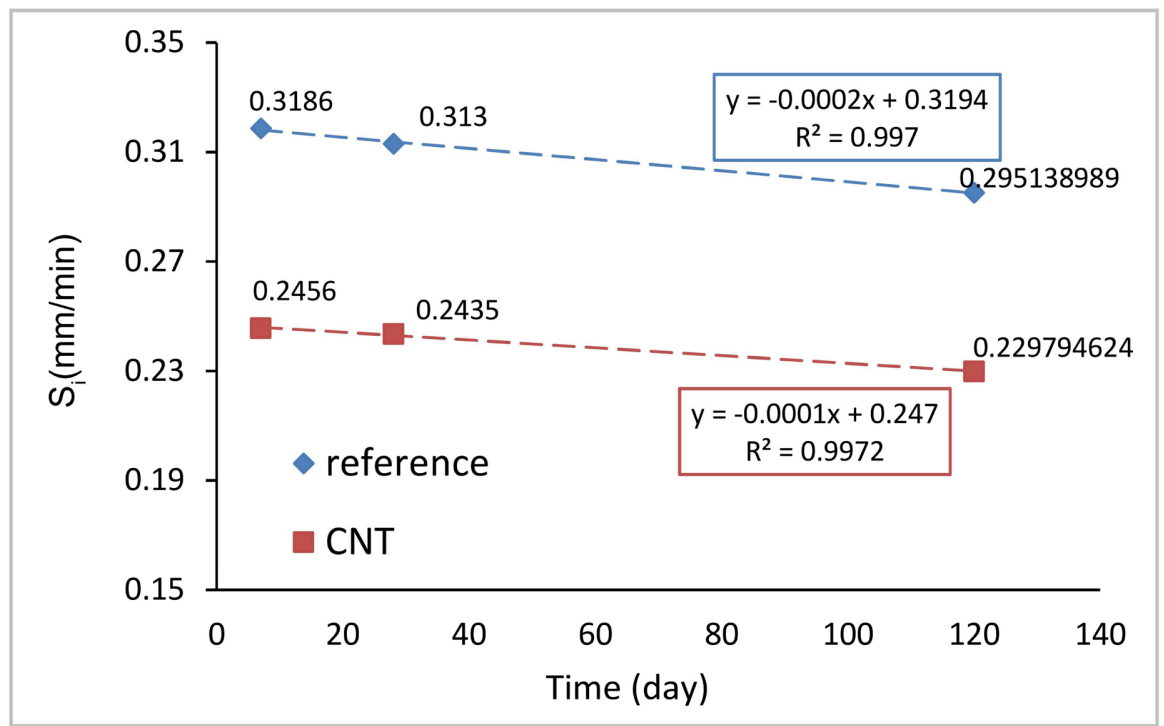

Figure 7. Capillary absorption $(\mathrm{mm} / \mathrm{min})$ for the CNT and REF mortars at times: 7, 28 and 120 days. 
This finding is also corroborated by the few available related studies found in the literature, where it was demonstrated that the addition of MWCNTs improved the physical properties of mortar [30] [31] [32], whereby, according to the test parameters reported, relatively low amounts of CNTs $(0.015 \%-0.2 \%$ wt.\% by cement weight) were added in the mortar. The studies reported that: 1 ) the physical properties of mortar can be enhanced when carboxyl MWCNTs were used in concrete production, while 2) the dispersion method also played a significant role on the properties of the hardened end product. In general, different methods were used to achieve a uniform distribution of CNTs in the cement matrix, such as using surfactants, treatment with acids, grinding, sonication etc. [33] [34] [35]. Konsta-Gdoutos et al. and Wang et al. [36] [37] reported that when the nanomaterials were added without using surfactant, MWCNTs exhibited poor dispersion in the mixture and large agglomerates and bundles were observed. Since the CNTs have strong tendency to agglomerate due to the presence of van der Waals forces, the use of MWCNTs dispersed by applying ultrasonic energy in combination with surfactant produced concrete with a dense structure and developed physical-mechanical properties.

\subsection{Flexural Strength}

The average bending strength values of mortars and their standard deviations are illustrated in Figure 8. The test results showed that the addition of CNTs in the mortar mixtures resulted in a consistently monotonic increase in the flexural strength of the mortar in all ages tested, compared to the REF group. More specifically, considering the measured evolution of $\sigma_{f f}$ from Equation (1), it can be seen that at 7 days the mortars with added CNTs exhibited an increase in the flexural strength of $8.3 \%$, while, at a more mature age of 28 days, the strength gain was maintained at $7.6 \%$. Furthermore, a small content of CNTs in the mortar has a major effect on the strength at 120 days; in this case, the strength of composites increases by $8.5 \%$ compared to the REF mortar.

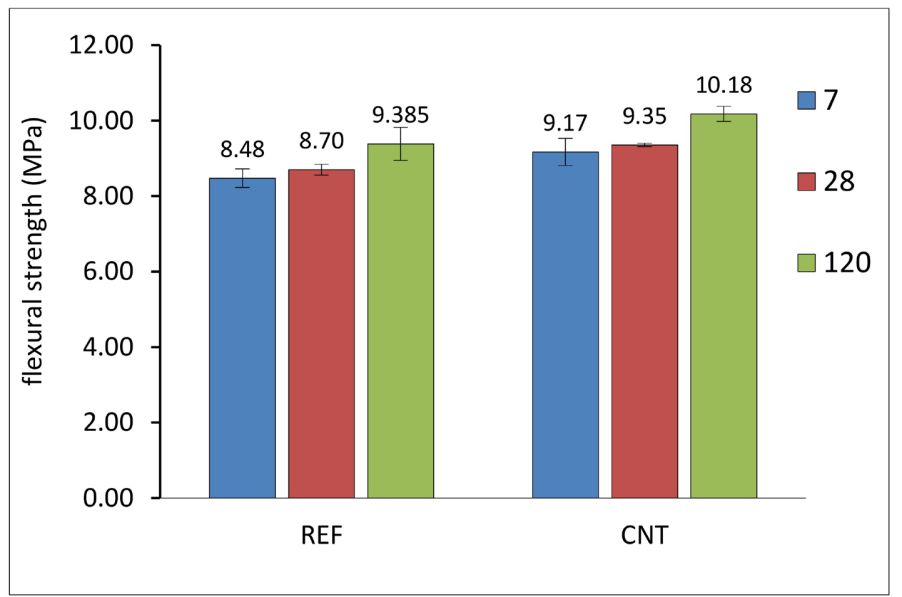

Figure 8. Average values of flexural strength $(\mathrm{MPa})$ for mortars prepared in the study. 
The strength improvement in flexure may be the evidence of an improved bonding and cohesion between CNTs and the cement matrix. In addition, CNTs additions in mortar enhance its resistance through initial and gradual micro-cracking limitation; at the same time, the nanomaterials bridge the macro-cracks, thus delaying the crack propagation and improving the toughness [38] [39] [40] of the hardened paste. CNTs due to their chemical composition and surface area most probably interact with cement, leading to the observed strength enhancement. In addition to the above, due to its fineness $\left(>500 \mathrm{~m}^{2} / \mathrm{kg}\right)$, CNTs probably act as a filler in the mixture, thus further reducing the pore size of the hardened composite and generating more nucleation sites to accelerate hydration reactions [41]; this nucleation effect influences the hydration process of the mortar by enhancing the crystallinity of the cementitious materials and leads to improved mechanical properties of the nanomaterial enriched cement composites. Makar et al. [42] [43] in their experimental study reported that the incorporation of CNTs in concrete accelerated the hydration process at early age. The authors considered that the latter effect was attributed to the polarization and adsorption between cement particles and CNTs, where the nano-size effect of CNTs provided the nucleation points for the hydration products. The researchers also proved the CNTs' addition effect on the hydration process and the morphology of hydration products $\left(\mathrm{C}_{3} \mathrm{~S}\right.$ and $\left.\mathrm{C}_{3} \mathrm{~A}\right)$.

These findings are also corroborated in the common mortar strength modified with CNTs of the present study: in Figure 9, the microscopy images by SEM of the microstructure of the nanocomposite mortars obtained on flat, polished surfaces of the CNT mortars used in this study, are depicted. These SEM analyses indicate that the nanomaterials demonstrate a network structure that can allow the bridging between narrow cracks in mortar (Figure 9(c)); in addition, it is clearly evident that the interfacial transition zone (ITZ) between cement and aggregates fills with CNTs resulting in a dense and solid structure of cement mortar (Figure 9(a)).

\subsection{Corrosion Measurements}

\subsubsection{Half-Cell Potential (HCP)}

The diagram in Figure 10 illustrates the half-cell corrosion potential (HCP) measurements, using a $\mathrm{Ag} / \mathrm{AgCl}$ reference electrode for both test specimen groups (REF and CNT) under investigation. As mentioned above, each group consists of eighteen (18) reinforced mortars partially immersed in sodium chloride $(\mathrm{NaCl})$ solution, and, therefore, each value shown in the diagram below is the average of those 18 test samples. The measurements were carried out over a period of eleven (11) months. From the results, it is observed that the groups under investigation are in an active state with increased possibility of pitting corrosion. Furthermore, it should be noted that the mortar specimens were immersed in $\mathrm{NaCl}$ $3.5 \mathrm{wt} \%$ after 48 hours from demolding. 


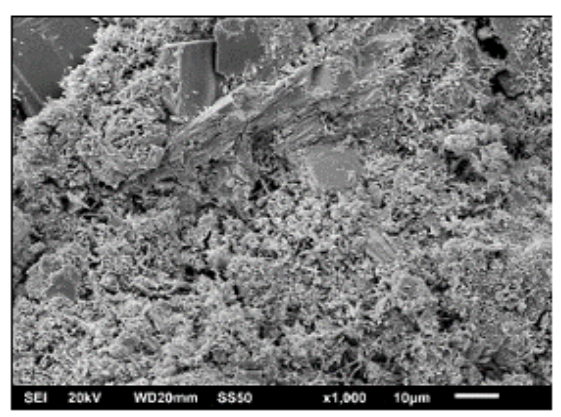

(a)

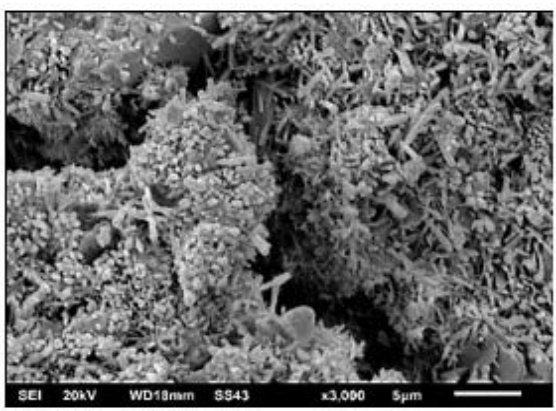

(c)

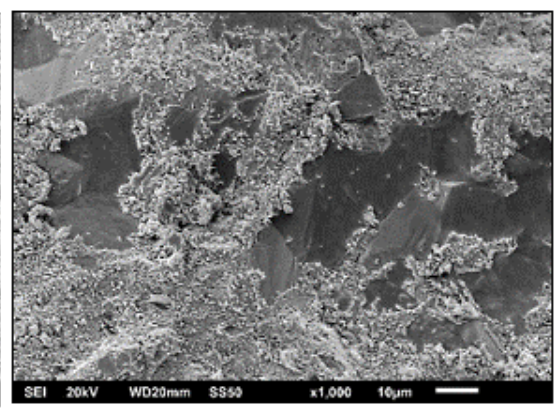

(b)

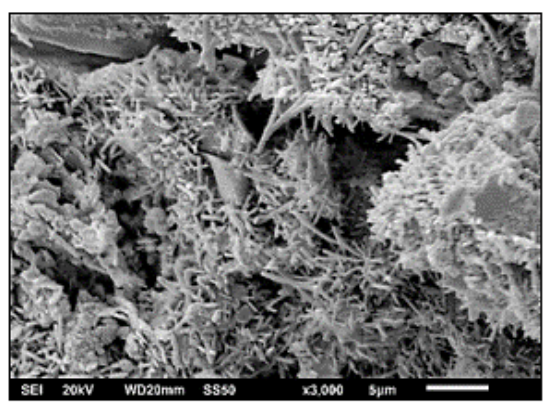

(d)

Figure 9. SEM images of the CNT mortars: (a) dense structure of mortar, b) ITZ between cement-aggregates; (c), (d) crack bridging due to the presence of CNTs. The SEM images also depict the proper dispersion of CNTs in the mixes.

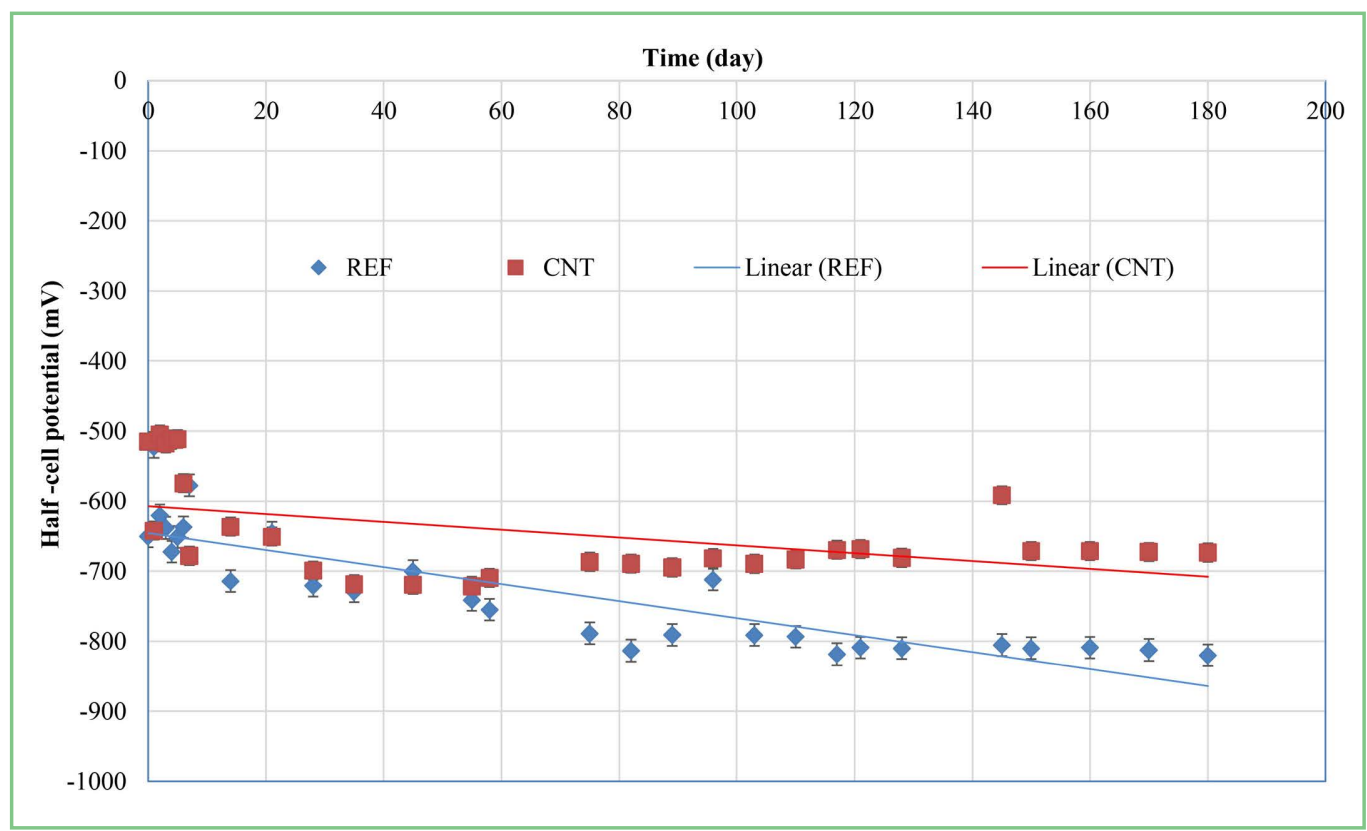

Figure 10. Half-Cell Potential $(\mathrm{mV})$ measurements using a $\mathrm{Ag} / \mathrm{AgCl}$ reference electrode against exposure time in $3.5 \mathrm{wt} \% \mathrm{NaCl}$ solution.

The results of the HCP on the CNT specimens in the present study were compared in Figure 10 with the corresponding HCP measurements on the REF specimens, established previously in [44], where mortar specimens with the same 
reference mix design were exposed to similar wet-dry cycles. From the comparison of the two, it is evident that with the addition of CNTs in the mortars, the values of the corrosion potentials are more electropositive than those of the REF specimens throughout the measurement period. More specifically, it is observed that, during the first 7 days of partial immersion in sodium chloride solution, the steel reinforcement embedded in mortars without CNTs are more corroded, because the values of the corrosion potentials measured are about $150 \mathrm{mV}$ more electronegative than the values of the potentials for corrosion of the group containing CNTs as additive. As the test progressed, after a period of 14 days in a corrosive environment, it was observed that both groups have moved towards more electronegative values of potentials, but the difference of about $150 \mathrm{mV}$ remained, implying that the reinforcement in the CNT group was relatively more protected than that of the REF group. Overall, the potential values of the specimens with CNTs are systematically more electropositive than the REF specimens, with the relative difference between the two types varying gradually with time.

After an elapsed period of 6 months, it was observed that the REF group moved to more electropositive values, something which may be attributed to the presence of corrosion products that temporarily protected the surface of the reinforcement. However, when these corrosion products dissolved, the potential values return to the levels expected, as shown by the corrosion potential values after a period of 11 months. In contract, the CNT group remained relatively stable between the time from 150 and 330 days, yielding an exponential decay factor for the half cell potential which was less than $50 \%$ of the REF mortar mix. It can be also observed that for the groups under investigation (CNT and REF), the HCP ranges between $700-830 \mathrm{mV}$ from 50 days onwards; this is attributed to the presence of sodium chloride, in which the mortars were partially immersed, resulting to the pitting corrosion on the steel's surface. This is in agreement with the findings of other studies, see [45] [46] [47] [48].

\subsubsection{Corrosion Current}

Figure 11 shows the corrosion current $\left(I_{\text {corr }}\right)$ for the two mortar groups under investigation; from the beginning of the immersion in $\mathrm{NaCl} 3.5 \mathrm{wt} \%$, the reinforcement bars seem to be in an active state of corrosion, being in the depassivation region of the reinforcement corrosion state (Table 3). The measurements of corrosion current show that both types of reinforced mortar specimens were corroded when exposed to $\mathrm{Cl}^{-}$ions. Furthermore, during the period of 11 months of measurement, it was observed that the REF group had the highest values in the corrosion current, compared to the CNT mixture. In particular, during the aforementioned period, the corrosion current of the REF specimens was $17 \%$ higher than that of CNT specimens. It is worth noting that the higher percentage change between the two groups tested was observed at 240 days, with a value of around $41 \%$. 


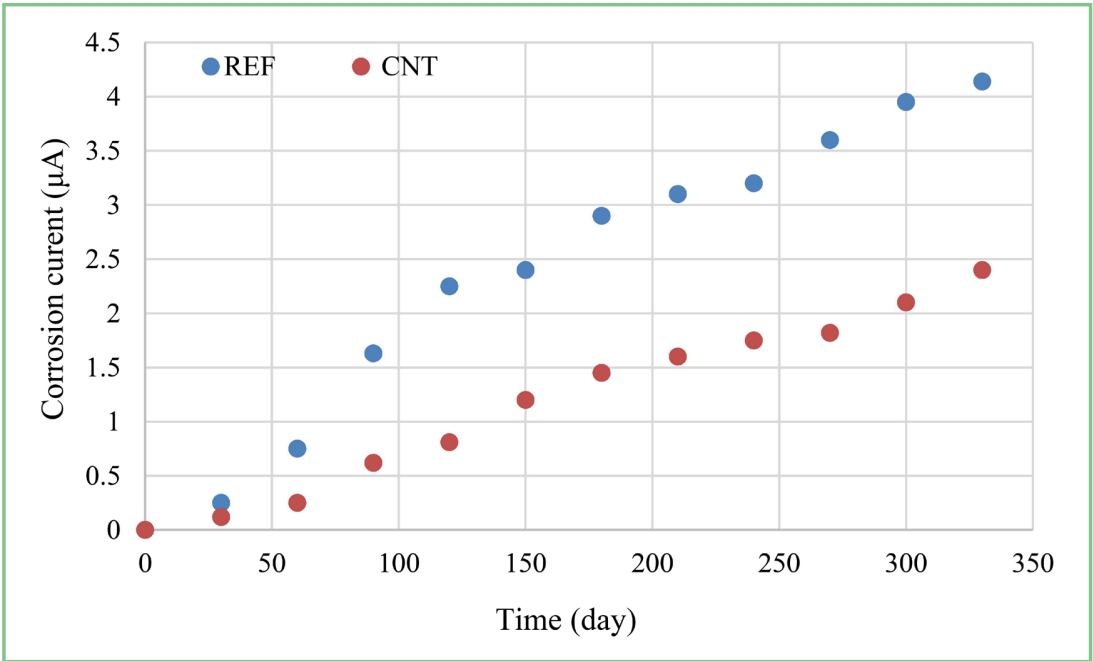

Figure 11. Corrosion current for the two mortar groups against time of exposure in $\mathrm{NaCl}$.

The addition of carbon nanotubes to mortars affects the durability of mortars in several ways [49]: the conductivity of mortar increases, the contact of steel with carbon leads to a galvanic element leading to increased oxidation of steel, the diameter of the mortar pores is reduced, and the mortar cracks are reduced and bridged and, generally, the micromorphology of the mortar is smoothed.

In terms of corrosion of the reinforcement, the conductivity of the mortar is also affected. When the CNTs are properly bonded with the reinforcement they can restrain crack formation, thereby improving load transfer and increased ductility of the composite structural material. However, the corrosion of the steel reinforcing bars embedded in cement mortars increases, especially when the CNT concentration is above a limit and percolation initiates, changing drastically the material properties. In the experimental investigation of Hall et al. [19], it was proven that, when the concentration of CNTs in the mortar exceeds the value of $0.5 \%$ by weight of cement, cement, corrosion increases dramatically. For this reason, a concentration of CNTs $0.2 \%$ by weight of cement was chosen in this study.

\subsubsection{Chloride Content in Mortars}

From the results illustrated in Figure 12, the REF and CNT specimens have similar chloride content values, measured by titration of $\mathrm{AgNO}_{3}$. In addition, after 9 months of partial immersion in chloride salt, there is a slight increase in the amount of total chlorides. In particular, the REF group exhibits $7.4 \%$ higher value of $\mathrm{Cl}^{-}$content than that of the CNT group at 9 months, while the corresponding value at 6 months was $8 \%$. At the same time, it can be seen from the test results that the chloride content has increased from 6 to 9 months for the two mixtures; more precisely, the relative increase of the REF specimens at 6 months was $3.1 \%$, while for the CNTs specimens was 3.6\%. 


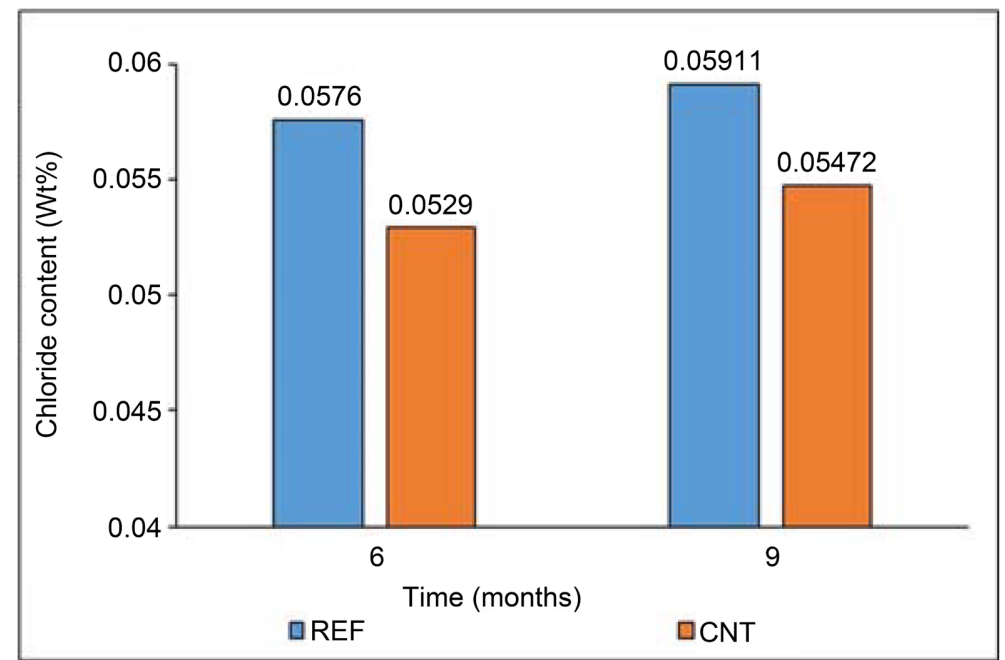

Figure 12. Total chloride contents (wt\%) in mortars partially immersed in $3.5 \mathrm{wt} \% \mathrm{NaCl}$ solution for 9 months.

\subsubsection{Mass Loss of the Steel Reinforcing Bars}

Figure 13 depicts the average mass loss of three (3) steel reinforcing bars after exposure in chloride salt at 6 and 9 months. It is observed that the REF specimens have a higher mass loss than the CNT mortar specimens at both ages considered, while, it is important to notice that the average mass loss of the REF specimens was twice that of the CNT specimens. In addition to the gravimetric measurements, values of the electrochemical mass loss were also calculated according to Faraday's law [50] [51], using the measurements of the corrosion current $\left(I_{\text {corr }}\right)$, and are also reported in Figure 13.

It can be seen from both measurements of mass loss (Gravimetric/Electrochemical) that the REF specimens are more corroded than the CNT specimens. For the 6-month period in a corrosive environment, the mass loss of the REF specimens was $50 \%$ greater than the mass loss of the CNT specimens. At the same time, for the period of 9 months exposure in $\mathrm{NaCl}$, the mass loss of the reinforcement was $28 \%$ higher in the REF group compared to the CNT group.

The corrosion behavior of the specimens is similar when calculating the electrochemical loss based on the Faraday law. The electrochemical mass loss compared to gravimetric mass loss differs in the result by about $15 \mathrm{mg}$, being greater than the gravimetric mass loss ( 9 months, Figure 13). This is systematic between these two types of measurements of the mass loss, and within the limits obtained in similar mass loss comparisons between Faraday's law and the gravimetric measurement.

The electrochemical measurements and gravimetric measurements of the mass loss are also confirmed by the total chloride content test results shown in Figure 12. The total chlorides in the REF specimens are higher than those of the CNT specimens, confirming the reduction of the diameter of the mortar pores with CNTs compared to the reference specimens. 


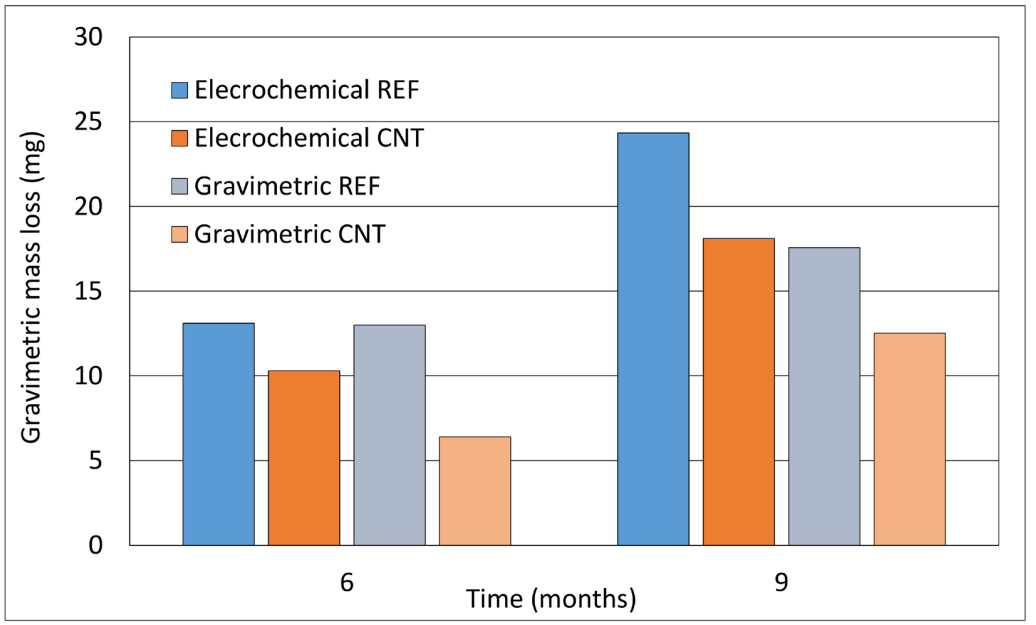

Figure 13. Gravimetric and electrochemical mass loss (mg) vs time, of the steel reinforcing bars embedded in mortars and partially immersed in $\mathrm{NaCl}$ for 9 months.

In conclusion, both the mass loss measurements shown in Figure 13 are and the chloride content measurements of the two types of mortars in Figure 12, demonstrate systematically that the steel reinforcing bars embedded in the CNT mortars exhibit higher chloride penetration resistance than the conventional reinforced specimens. Therefore, the addition of $0.2 \mathrm{wt} \%$ in the mortar mix also provides anticorrosion protection in the mortar reinforcement.

\section{Conclusions}

The results of an experimental study of the physical-mechanical and durability properties of common strength mortars with and without the inclusion of CNTs were presented and compared. Based on the findings of the tests and the discussion of the results, the following can be summarized in conclusion:

1) The addition of multi-walled CNTs improves the porosity and capillary absorption of cement mortars with time after immersion in $\mathrm{NaCl}$ solution.

2) In terms of measured half-cell potential, the introduction of CNTs on the mortars resulted in a reduction of $50 \%$ in the exponential decay factor of the measured half-cell potential.

3) The increase in the flexural strength (Figure 8) against time of exposure in corrosive environment is attributed to the change in the density of test specimens and the porosity (Figure 6). Electrochemical (corrosion current and half-cell potential) and chloride content measurements indicate the chloride penetration resistance and durability of CNTs mortars comparing with OPC specimens.

4) The mass loss of steel bars embedded in CNT-modified mortars is reduced, compared to those in the reference specimens; this confirms the anticorrosive effect of CNTs used at $0.2 \mathrm{wt} \%$ content in reinforced CNT modified mortar composites.

\section{Acknowledgements}

This research is co-financed by Greece and the European Union (European So- 
cial Fund-ESF) through the Operational Programme "Human Resources Development, Education and Lifelong Learning 2014-2020" in the context of the project "nanotechnology and metal fibers applications for the resistance of reinforced concrete exposed to highly corrosive environment" (MIS 5049426). Furthermore, the authors greatly appreciate the assistance of Professor Dr. I. Ioannou of the University of Cyprus, for providing us the facilities for performing the physico-mechanical tests and microscopical analysis. The views, statements and opinions presented in this paper are solely those of the authors.

\section{Conflicts of Interest}

The authors declare no conflicts of interest regarding the publication of this paper.

\section{References}

[1] Ozkan, T., Naraghi, M. and Chasiotis, I. (2010) Mechanical Properties of Vapor Grown Carbon Nanofibers. Carbon, 48, 239-244. https://doi.org/10.1016/j.carbon.2009.09.011

[2] EN 1992-1-1 (2004) Eurocode 2: Design of Concrete Structures-Part 1-1: General Rules and Rules for Buildings. European Committee for Standardization, Brussel.

[3] EN 206 (2004) Eurocode 2: Design of Concrete Structures-Part 1-1: General Rules and Rules for Buildings. European Committee for Standardization, Brussels.

[4] Bethune, D., Kiang, C., de Vries, M. et al. (1993) Cobalt-Catalysed Growth of Carbon Nanotubes with Single-Atomic-Layer Walls. Nature, 363, 605-607. https://doi.org/10.1038/363605a0

[5] Iijima, S. and Ichihashi, T. (1993) Single-Shell Carbon Nanotubes of 1-nm Diameter. Nature, 363, 603-605. https://doi.org/10.1038/363603a0

[6] Iijima, S. (1991) Helical Microtubules of Graphitic Carbon. Nature, 354, 56-58. https://doi.org/10.1038/354056a0

[7] Oberlin, A., Endo, M. and Koyama, T. (1976) Filamentous growth of carbon through benzene decomposition. Journal of Crystal Growth, 32, 335-349. https://doi.org/10.1016/0022-0248(76)90115-9

[8] Grunlan, J., Mehrabi, A., Bannon, M. and Bahr, J. (2004) Water-Based Single-Walled-Nanotube-Filled Polymer Composite with an Exceptionally Low Percolation Threshold. Advanced Materials, 16, 150-153. https://doi.org/10.1002/adma.200305409

[9] Salvetat, J.P., Bonard, J.M., Thomson, N., et al. (1999) Mechanical Properties of Carbon Nanotubes. Applied Physics A, 69, 255-260. https://doi.org/10.1007/s003390050999

[10] Liew, K.M., Kai, M.F. and Zhang, L.W. (2016) Carbon Nanotube Reinforced Cementitious Composites: An Overview. Composites Part A: Applied Science and Manufacturing, 91, 301-323. https://doi.org/10.1016/j.compositesa.2016.10.020

[11] Siddique, R. and Mehta, A. (2014) Effect of Carbon Nanotubes on Properties of Cement Mortars. Construction and Building Materials, 50, 116-129.

https://doi.org/10.1016/j.conbuildmat.2013.09.019

[12] Fenner, J.S. and Daniel, I.M. (2014) Hybrid Nanoreinforced Carbon/Epoxy Composites for Enhanced Damage Tolerance and Fatigue Life. Composites Part A: Applied Science and Manufacturing, 65, 47-56. 
https://doi.org/10.1016/j.compositesa.2014.05.023

[13] Han, B., et al. (2015) Review of Nanocarbon-Engineered Multifunctional Cementitious Composites. Composites Part A: Applied Science and Manufacturing, 70, 69-81. https://doi.org/10.1016/j.compositesa.2014.12.002

[14] Gdoutos, E.E., Konsta-Gdoutos, M.S. and Danoglidis, P.A. (2016) Portland Cement Mortar Nanocomposites at Low Carbon Nanotube and Carbon Nanofiber Content: A Fracture Mechanics Experimental Study. Cement and Concrete Composites, 70, 110-118. https://doi.org/10.1016/j.cemconcomp.2016.03.010

[15] Rovnaník, P., et al. (2016) Carbon Nanotube Reinforced Alkali-Activated Slag Mortars. Construction and Building Materials, 119, 223-229.

https://doi.org/10.1016/j.conbuildmat.2016.05.051

[16] Chaipanich, A., et al. (2010) Compressive Strength and Microstructure of Carbon Nanotubes-Fly Ash Cement Composites. Materials Science and Engineering. A, 527, 1063-1067. https://doi.org/10.1016/j.msea.2009.09.039

[17] Del Carmen Camacho, M., et al. (2014) Mechanical Properties and Durability of CNT Cement Composites. Materials, 7, 1640-1651.

https://doi.org/10.3390/ma7031640

[18] Konsta-Gdoutos, M.S., et al. (2017) Effect of CNT and CNF Loading and Count on the Corrosion Resistance, Conductivity and Mechanical Properties of Nanomodified OPC Mortars. Construction and Building Materials, 147, 48-57. https://doi.org/10.1016/j.conbuildmat.2017.04.112

[19] Hassan, A., Elkady, H. and Shaaban, I.G. (2019) Effect of Adding Carbon Nanotubes on Corrosion Rates and Steel-Concrete Bond. Scientific Reports, 9, Article No. 6285. https://doi.org/10.1038/s41598-019-42761-2

[20] EN 12390-8 (2009) Testing Hardened Concrete. Depth of Penetration of Water under Pressure. British Standard Institution, London.

[21] Hall, C. and Tse, T.K.M. (1986) Water Movement in Porous Building MaterialsVII. The Sorptivity of Mortars. Building and Environment, 21, 113-118. https://doi.org/10.1016/0360-1323(86)90017-X

[22] Gummerson, R.J., Hall, C. and Hoff, W.D. (1980) Water Movement in Porous Building Materials II. Hydraulic Suction and Sorptivity of Brick and Other Masonry Materials. Building and Environment, 15, 101-108. https://doi.org/10.1016/0360-1323(80)90015-3

[23] ASTM C876-87 (2002) Standard Test Method for Half-Cell Potentials of Reinforcing Steel in Concrete. ASTM International.

[24] Chousidis, N., Rakanta, E., Ioannou, I. and Batis, G. (2015) Mechanical Properties and Durability Performance of Reinforced Concrete Containing Fly Ash. Construction and Building Materials, 101, 810-817. https://doi.org/10.1016/j.conbuildmat.2015.10.127

[25] Zafeiropoulou, T., Rakanta, E. and Batis, G. (2013) Carbonation Resistance and Anticorrosive Properties of Organic Coatings for Concrete Structures. Journal of Surface Engineered Materials and Advanced Technology, 3, 67-74. https://doi.org/10.4236/jsemat.2013.31A010

[26] Rashad, A.M. (2017) Effect of Carbon Nanotubes (CNTs) on the Properties of Traditional Cementitious Materials. Construction and Building Materials, 153, 81-101. https://doi.org/10.1016/j.conbuildmat.2017.07.089

[27] Shi, T., et al. (2019) Research Progress on CNTs/CNFs-Modified Cement-Based Composites-A Review. Construction and Building Materials, 202, 290-307. 
https://doi.org/10.1016/j.conbuildmat.2019.01.024

[28] Gao, Y., et al. (2021) Roles of Carbon Nanotubes in Reinforcing the Interfacial Transition Zone and Impermeability of Concrete under Different Water-to-Cement Ratios. Construction and Building Materials, 272, Article ID: 121664. https://doi.org/10.1016/j.conbuildmat.2020.121664

[29] Abu Taqa, A.G., et al. (2015) The Effect of Interfacial Transition Zone Properties on the Elastic Properties of Cementitious Nanocomposite Materials. Journal of Nanomaterials, 2015, Article ID: 258384. https://doi.org/10.1155/2015/258384

[30] Hu, Y., et al. (2014) Fracture Toughness Enhancement of Cement Paste with Multi-Walled Carbon Nanotubes. Construction and Building Materials, 70, 332-338. https://doi.org/10.1016/j.conbuildmat.2014.07.077

[31] Kang, S.T., Seo, J.Y. and Park, S.H. (2015) The Characteristics of CNT/Cement Composites with Acid-Treated MWCNTs. Advances in Materials Science and Engineering, 2015, Article ID: 308725. https://doi.org/10.1155/2015/308725

[32] Han, B., Zhang, K., Yu X., et al. (2013) Transport Properties of Carbon-Nanotube/Cement Composites. Journal of Materials Engineering and Performance, 22, 184-189. https://doi.org/10.1061/(ASCE)MT.1943-5533.0000435

[33] Han, B., Zhang, K., Yu X. and Kwon, E. (2012) Fabrication of Piezoresistive CNT/ CNF Cementitious Composites with Superplasticizer as Dispersant. Journal of Materials in Civil Engineering, 24, 658-665. https://doi.org/10.1061/(ASCE)MT.1943-5533.0000435

[34] Kim, H.K., Park, I.S. and Lee, H.K. (2014) Improved Piezoresistive Sensitivity and Stability of CNT/Cement Mortar Composites with Low Water-Binder Ratio. Composite Structures, 116, 713-719. https://doi.org/10.1016/j.compstruct.2014.06.007

[35] Li, G.Y., Wang, P.M. and Zhao, X. (2005) Mechanical Behavior and Microstructure of Cement Composites Incorporating Surface-Treated Multi-Walled Carbon Nanotubes. Carbon, 43, 1239-1245. https://doi.org/10.1016/j.carbon.2004.12.017

[36] Konsta-Gdoutos, M.S., Metaxa, Z.S. and Shah, S.P. (2010) Highly Dispersed Carbon Nanotube Reinforced Cement Based Materials. Cement and Concrete Research, 40, 1052-1059. https://doi.org/10.1016/j.cemconres.2010.02.015

[37] Wang, B., Han, Y. and Liu, S. (2013) Effect of Highly Dispersed Carbon Nanotubes on the Flexural Toughness of Cement-Based Composites. Construction and Building Materials, 46, 8-12. https://doi.org/10.1016/j.conbuildmat.2013.04.014

[38] Wille, K. and Loh, K.J. (2010) Nanoengineering Ultra-High-Performance Concrete with Multiwalled Carbon Nanotubes. Transportation Research Record, 2142, 119-126. https://doi.org/10.3141/2142-18

[39] Esmaeili, J. and Mohammadjafari, A.R. (2014) Increasing Flexural Strength and Toughness of Cement Mortar Using Multi-Walled Carbon Nanotubes. International Journal of Nano Dimension, 5, 399-407. https://doi.org/10.7508/ijnd.2014.04.012

[40] Li, W.W., et al. (2015) Investigation on the Mechanical Properties of a CementBased Material Containing Carbon Nanotube under Drying and Freeze-Thaw Conditions. Materials, 8, 8780-8792. https://doi.org/10.3390/ma8125491

[41] Chousidis, N., Zacharopoulou, A.K. and Batis, G. (2020) Corrosion Protection of Reinforcement Steel Using Solid Waste Materials in Concrete Production. Magazine of Concrete Research, 72, 271-277. https://doi.org/10.1680/jmacr.17.00537

[42] Makar, J., Margeson, J. and Luh, J. (2005) Carbon Nanotube/Cement CompositesEarly Results and Potential Applications. Proceedings of the 3 rd International Conference on Construction Materials: Performance, Innovations and Structural Impli- 
cations, Vancouver, 22-24 August 2005, 1-10.

[43] Makar, J.M. and Chan, G.W. (2009) Growth of Cement Hydration Products on Single-Walled Carbon Nanotubes. Journal of the American Ceramic Society, 92, 1303 1310. https://doi.org/10.1111/j.1551-2916.2009.03055.x

[44] Qiao, G., et al. (2017) Corrosion Behavior of a Steel Bar Embedded in a Cement-Based Conductive Composite. Construction and Building Materials, 134, 388-396. https://doi.org/10.1016/j.conbuildmat.2016.12.087

[45] Voulgari, E., Zacharopoulou, A., Chousidis, N. and Batis, G. (2019) Corrosion Behavior of Reinforcement Steel Embedded in Cement Mortars Using Different Protection Systems. Materials Sciences and Applications, 10, 461-474. https://doi.org/10.4236/msa.2019.106034

[46] Voulgari, E., Zacharopoulou, A., Chousidis, N. and Batis, G. (2019) Effect of Organic Coating Corrosion Inhibitor on Protection of Reinforced Mortar. Journal of Materials Science and Chemical Engineering, 7, 20-34. https://doi.org/10.4236/msce.2019.71003

[47] Chousidis, N., Rakanta, E., Ioannou, I. and Batis, G. (2015) Anticorrosive Effect of Electrochemical Manganese Dioxide By-Products in Reinforced Concrete. Journal of Materials Science and Chemical Engineering, 3, 9-20. https://doi.org/10.4236/msce.2015.35002

[48] Česen, A., Kosec, T. and Legat, A. (2013) Characterization of Steel Corrosion in Mortar by Various Electrochemical and Physical Techniques. Corrosion Science, 75, 47-57. https://doi.org/10.1016/j.corsci.2013.05.015

[49] Wang, T., et al. (2020) Experimental Study on the Effect of Carbon Nanofiber Content on the Durability of Concrete. Construction and Building Material, 250, Article ID: 118891. https://doi.org/10.1016/j.conbuildmat.2020.118891

[50] Torabi, F. and Ahmadi, P. (2020) Chapter 2-Fundamentals of Batteries. In: Torabi, F. and Ahmadi, P., Eds., Simulation of Battery Systems, Academic Press, Cambridge, 55-81.

[51] Sundén, B. (2019) Chapter 2-Electrochemistry and Thermodynamics. In: Sundén, B., Ed., Hydrogen, Batteries and Fuel Cells, Academic Press, Cambridge, 15-36. https://doi.org/10.1016/B978-0-12-816950-6.00002-6 